\title{
A model, describing the influence of water management alternatives on dike stability
}

\author{
J. W. M. Lambert, E. Vastenburg, and F. J. Roelofsen \\ Deltares, Delft, the Netherlands \\ Correspondence to: J. W. M. Lambert (john.lambert@deltares.nl) \\ Published: 12 November 2015
}

\begin{abstract}
The awareness is rising that economic effects of Land Subsidence are high. Nevertheless, quantifying these economic losses is difficult and, as far as known, not yet done in a sophisticated way. Also, to be able to decide about future strategies, for example to avoid or decrease subsidence, it is necessary to know the financial consequences of measures and possible solutions. As a first step to quantify these economic effects, a MODFLOW-SCR (coupled MODFLOW-Settlements model) is coupled with the model DAM. Based on the local stratigraphy, the shape and composition of the existing dike or levee, the level of the surface water and the surface level, macro-stability of the dike is calculated and - if the dike does not meet the required stability adaptions are proposed. The model enables to separate effects that are caused by sea-level rise and the effects of subsidence. Coupling the DAM model with an economic model to calculate costs of these adaptions is under construction.
\end{abstract}

\section{Introduction}

Dikes and levees are designed and constructed to safeguard people and economic interests from flooding. The minimum height of a dike is derived from the maximum expected water height and may be reduced by accepting a certain frequency of overflow. In design, a future increase of the water height, due to climate change, is taken into account. Besides the criterion of required height, criteria of stability and piping play an important role. In this paper mechanisms that play a role in dike-safety, will be discussed and a model is presented that enables to assess the long term influence of water management and climate change effects on dike stability. A casestudy for Delft in the Netherlands has been elaborated. This coupled groundwater - subsidence - dike stability model can be considered as a first step and a show case in the future development of a water management support system.

\section{Case-study Delft}

In Delft, industrial groundwater extraction of about $1200 \mathrm{~m}^{3} \mathrm{~h}^{-1}$ by DSM (an industrial site) takes place since the early 20th century. The groundwater has been used for cooling purposes and caused seasonal fluctuations in the piezo- metric levels in the Pleistocene aquifers in the order of $6 \mathrm{~m}$ and could be observed in a radius of about $20 \mathrm{~km}$ from the extraction. The groundwater abstraction also caused subsidence with a maximum of about $0.50 \mathrm{~m}$.

After DSM decided to stop groundwater abstraction, the possible effects in terms of piezometric levels were predicted with a groundwater model and - parallel - a subsidence model was developed to enable forecasting of possible resulting land raise.

As the groundwater abstraction has lasted many decades and it was never expected it would ever stop, possible effects of a rising water table were never taken into account in design and construction of buildings and infrastructure. These effects have been investigated one by one and it was concluded that they are so uncertain that the municipality of Delft, the Province of South Holland and the waterboard Delfland decided to maintain the abstraction until 2017, taking mitigating measures in the meantime and install a monitoring network to support stepwise decrease of the extraction rate during the years after 2017. 


\section{Failure mechanisms of dikes and levees}

Each dike is assessed on a regular base to establish its functionality under possible - future - extreme circumstances. Controlled mechanisms are: e.g. overtopping and piping.

More complicated mechanisms are outward and inward stability of the dike. The driving force in instability is the weight of the dike body, taking into account the difference of wet and dry volumetric weight and the shape of the dike. Under extreme low (river-level) conditions outward instability should be controlled and under extreme high conditions the inward stability should be guaranteed. As indicated; for these mechanisms, the weight of the dike plays an important role, but also - in case of inward instability - the water pressure at the outside and the groundwater conditions in and under the dike. These mentioned forces have to be resisted by friction forces in the soil. The allowable forces are strongly dependent from the soil, but also water pressures play an important role. This is especially the case if piezometric levels in the (sandy) subsoil are more or less in balance with the (clay or peaty) covering layers on top. In such cases, which are rather common in the Netherlands, the critical slip circle may change because - at least theoretically - the resistance against slip becomes almost frictionless where the piezometric level is in balance with the weight of the covering layer.

Climate change and water management strategies cause boundary conditions for dike safety change in time. The developed model is able to predict the influence of different strategies on dike safety and such it can support decision making.

\section{The models}

\section{1 iMOD}

iMOD (Vermeulen, 2006) is an easy to use Graphical User Interface and an accelerated version of the well-known MODFLOW 3-D Groundwatermodel. Modflow was developed by USGS in the eighties of the past century; the iMOD version has been developed by Deltares in co-operation with USGS. The main feature of iMOD is that it allows gathering all available input data at its available resolution, where iMOD enables up- and down-scaling towards the model area and grid resolution that is required for a specific user-defined problem. So, different sources of information can easily be combined and applied in whatever resolution as required. Shifting the area of interest or changing the resolution can easily be done.

\subsection{SCR-module}

SCR (Settlement Creep) is an extension on MODFLOW that is recently developed by Deltares in co-operation with USGS; the SCR-module enables to predict the influence of changing groundwater levels and piezometric levels on land

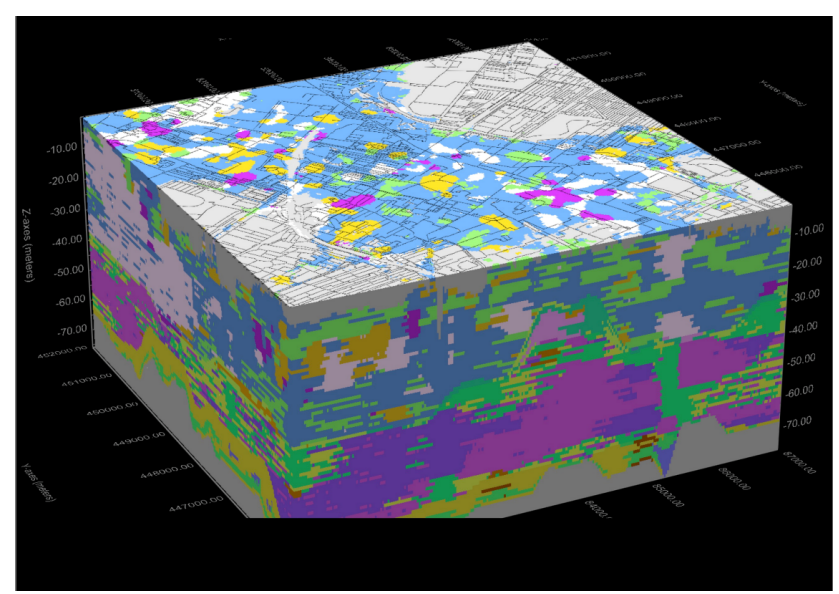

Figure 1. 3-D Geological model on a scale of $100 \times 100 \times 0.5$ $(L \times W \times H)$ based on all available boreholes and CPTs. Colors indicate variation in lithology and are user-defined. The picture indicates the heterogeneity of the subsoil (pink = peat, green and blue are different clays, yellow are Holocene sands).

subsidence. The new module simulates groundwater storage changes and compaction in discontinuous interbeds or in extensive confining units, accounting for temporal and spatial variability of geostatic and effective stresses. It implements two methods of compaction (settlement) calculation accounting for secondary compaction (i.e. creep). The NEN-Bjerrum and the Isotache methods are included in the new package. The first method adapts a linear strain relationship while the second adapts a natural strain relationship to calculate compaction/settlement. Several features of the package make it useful for application in shallow, unconfined flow systems.

\subsection{DAM}

DAM is a Dike Analysis Module that evaluates the safety of levees and dams against instability under present and under decisive (e.g. high tide) circumstances. Surface levels, the phreatic levels and the piezometric levels are important input for this analysis, besides possible change in the decisive level, as a result of climate change. DAM analysis and presents dike-stability according to Bishop theory, possible uplift and seepage erosion. Coupling of DAM to iMOD-SCR allows to predict the effect of possible water management decisions on dike safety.

\section{Results of the case-study}

In 2008, a preliminary model-study was carried out to predict the effects of stopping the groundwater extraction in terms of piezometric and phreatic groundwater levels. These results were exported from MODFLOW and imported in DSettle (a 2-D-settlement model) to predict changes in surface level in specified cross-sections. Separately, the predicted phreatic 


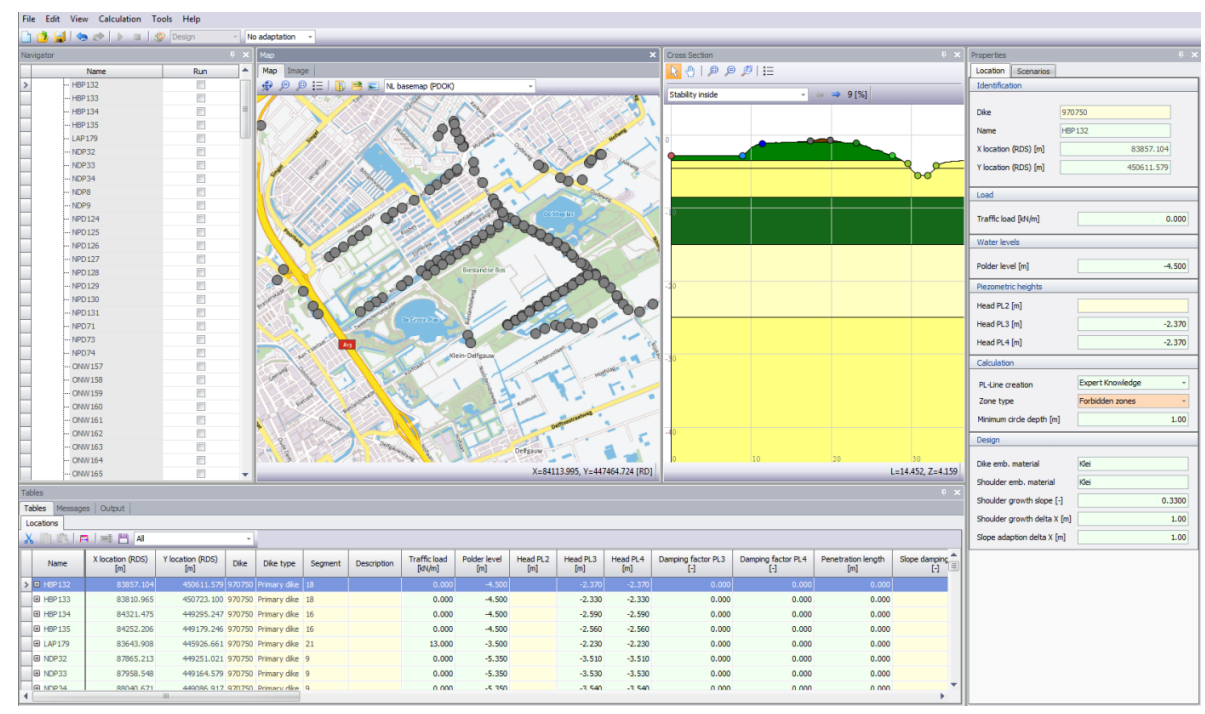

Figure 2. Cross-sections in DAM.

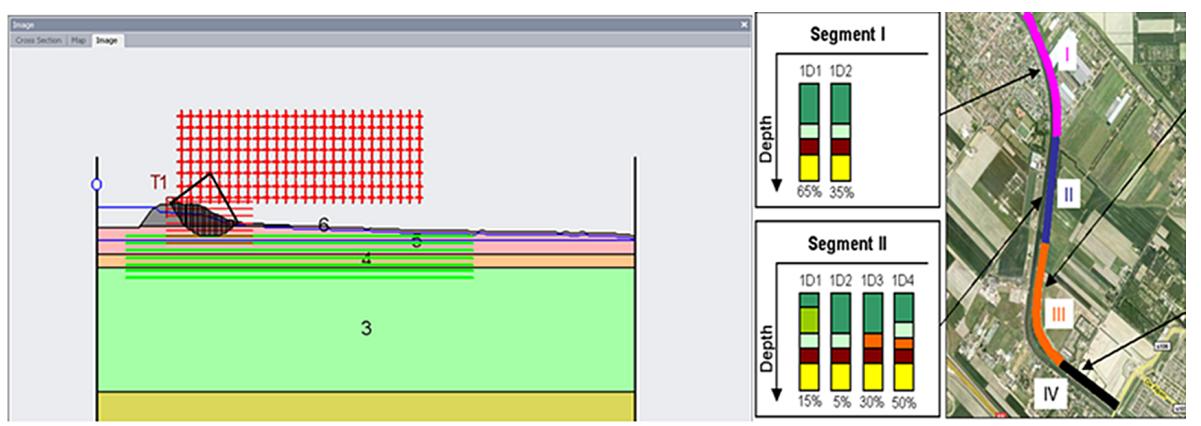

Figure 3. Input and results DAM-calculations. The figure shows one cross-section, representing Segment II for which - statistically - a distribution of possible geological settings is estimated. The grid represents all possible slip circlesof which the most critical is established by calculating them all.

and piezometric changes were imported in DStab to predict effects on levees and dikes. Also, the effects of stopping groundwater extraction on buildings, infrastructure and other effects had to be assessed. All effects had to be assessed more or less manually, and were therefore very time-consuming. Therefore, an optimization of scenarios never took place and it was decided to install a monitoring network, take already a number of mitigating measures and - after 2017 - decrease the extraction rate step-wise.

Using the integrated iMOD-SCR-DAM model, the effects of stopping the groundwater extraction on dike stability, were repeated, which gave a much more detailed insight in the effects of the management decisions and also giving the opportunity to compare the effects of different strategies.

Figure 1 shows the geological model that is based on an interpretation of all available CPT and borehole data and in Fig. 2 the calculated DAM locations are given, as well as a typical cross-section.
Figure 3 shows the input of the DAM-model as it is derived from iMOD and - following - all possible slip-circles through the dam body are calculated simultaneously, selecting the most critical of them and calculating the safety factor against instability.

The results of this calculation are given in Fig. 4, in terms of a decrease of the safety factor.

\section{Conclusions}

Although groundwater abstraction has many negative effects, decrease or even stopping abstraction can also cause negative effects, such as possible instability of dikes and levees. In this paper these negative consequences on dike stability have been elaborated.

Decision makers need insight in the consequences of their decisions. The quicker this insight can be given; the better an optimum can be proposed. For this reason, coupling of already existing models that describe the effects of alterna- 


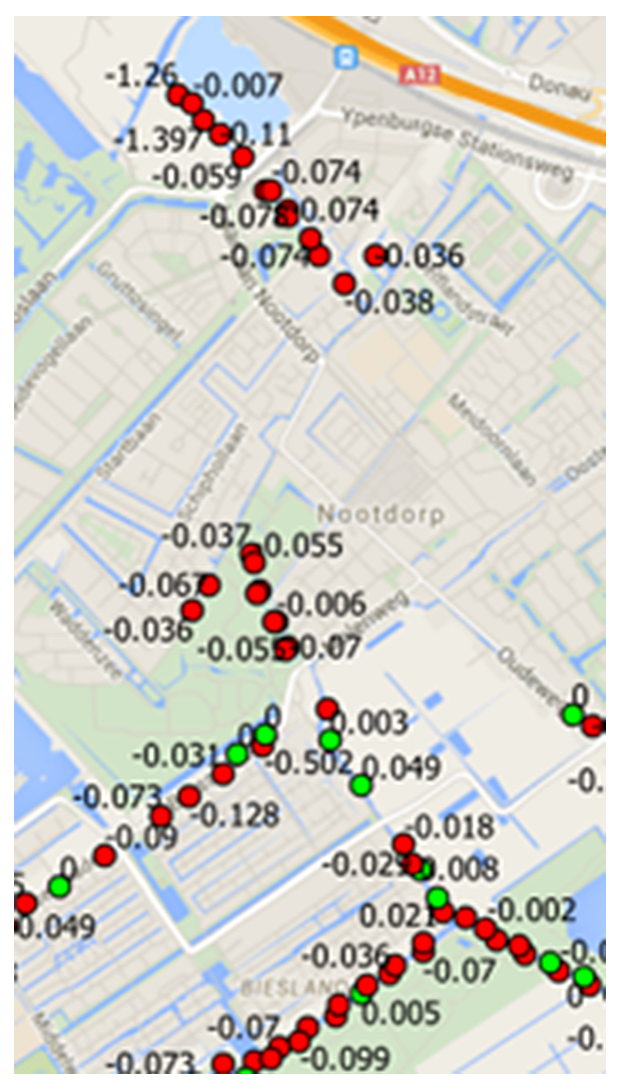

Figure 4. Calculated change in stability factor. Green dots mean an increase of the safety factor while the red ones indicate a decrease. The indicated values are the calculated decrases and increases.

tives is important. Presented is a model that describes the effects on dike stability of alternatives in water management and - from the results - costs can be derived rather easily. The results of the calculations give a quick insight in the locations that need to be adapted; alternative scenarios can be elaborated quickly, such that advantages and disadvantages of different decisions become clear and an optimum can be chosen.

\section{Future developments}

Given the complex connections between cause and effects of alternative water management decisions, development of models that quantify these effects are urgently required. The described interconnection between a groundwater - subsidence model and a model that controls dam stability is an example how existing models can easily be coupled and give information on the effects of different decisions. This shown example should be seen as a first step in coupling the groundwater - subsidence model to other models that describe effects, such as effects on foundations, effects on infrastructure and consequences on flooding. Future developments will also contain coupling with economic models and adding a module that enables to predict the effects of loading the subsoil. Although this seems (and is) a huge amount of work, it should be considered that - in common - existing models are already available and can be integrated rather easily.

Acknowledgements. The activities for this development were funded by Deltares.

\section{References}

Bakr, M.: Coupled Modeling of Groundwater Flow and Land Subsidence With Creep (MODFLOW/SUB-CR), 2012.

Vermeulen, P. T. M.: Model-Reduced Inverse Modeling, PhD thesis, Delft University of Technology, Delft, 2006. 